\title{
7 CAN WILLOW ROOTS OXYGENATE LEACHATE IN VEGETATION FILTER BEDS? - A MASS SPECTROMETER INVESTIGATION IN WALES
}

\author{
Haydn G. Williams and Peter F. Randerson \\ Cardiff University, School of Biosciences, Cardiff, Wales, U.K. \\ Fred M. Slater and Rebecca J. Heaton \\ Cardiff University, Field Centre, Newbridge on Wye, Wales, U.K. \\ (The Salix Project www.salix.org.uk)
}

\begin{abstract}
Membrane inlet mass spectrometry (MIMS) was used to monitor dissolved gas concentrations in-situ in laboratory microcosms and in a constructed willow vegetation filter bed in Wales used to treat leachate. A mini-rhizotron digital camera system was developed for use in combination with MIMS studies of gas dynamics. The major results of the studies are:-

- Diurnal cycles in the concentrations of $\mathrm{O}_{2}, \mathrm{CO}_{2}$ and $\mathrm{CH}_{4}$ were shown to occur with a rooted willow cutting in a stirred microcosm.

- Willow beds show considerable sub-surface spatial diversity. Generally, oxygen decreases with depth whereas methane and carbon dioxide increase with depth. Small pockets of gases were seen. Oxygen occurred throughout the profile.

- Microbial processes follow diurnal cycles. Oxygen is released from willow roots during daylight. Methane and carbon dioxide accumulate during the dark.

- The high degree of mixing distributes oxygenated water throughout the bed. Stopping the flow of leachate allowed conditions to become anaerobic, except in local micro-sites.

These techniques appear to offer considerable potential for direct measurement of sub-surface environments in constructed wetlands, particularly in respect of the microbial processes occurring in the bed, and the oxygenation capacity of willow vegetation filters.
\end{abstract}

\section{KEYWORDS}

Willow vegetation filters, constructed wetlands, leachate treatment, membrane inlet mass spectrometry, mini-rhizotron camera, oxygenation, microbial processes.

\section{INTRODUCTION}

Constructed wetlands (Vegetation Filters) are artificial complexes of water, matrix, vegetation and the associated invertebrate and microbial communities designed to simulate the ability of natural wetlands to remove pollutants from water (1). They provide an inexpensive and reliable method for treating a variety of waste waters such as sewage, landfill leachate, mine leachate, agricultural run-off,' and are comparatively simple to construct, operate and 
maintain. It is well known that different designs of constructed wetlands result in different sub-surface environments. In particular, in Horizontal Flow (HF) beds, oxygen availability is predominantly low, so that the rate of aerobic processes such as breakdown of organic matter, and nitrification of ammonia, is typically limited. The design of Vertical Flow (VF) beds was intended to aid the aeration of the bed with atmospheric oxygen using a pulsed input of waste water to the surface, hence increasing the efficiency of pollutant breakdown. However, removal of nitrogen by denitrification and breakdown of some organic materials depends on anaerobic conditions. Multi-stage systems, alternating HF and VF stages, subject the flow of water to a range of environments in successive beds.

Within the sediment matrix of a vegetation filter bed, it is asssumed that different microenvironments coexist, with micro-gradients of oxygenation, especially in association with the rhizosphere zone surrounding plant roots. Gradients of dissolved oxygen and redox potential associated with the boundaries of aerobic zones, have been measured using micro-electrodes in soil and stream sediments respectively (2). Such micro-gradients determine the location of particular microbial processes within the sediment matrix of the bed (Table 1).

\begin{tabular}{|c|c|c|c|c|}
\hline Status & anoxic & anaerobic & $\Leftrightarrow$ & aerobic \\
\hline 'Zone' & $\mathrm{CH}_{4}$ & $\mathrm{H}_{2} \mathrm{~S}$ & $\mathrm{NH}_{3}$ & $\mathrm{O}_{2}, \mathrm{CO}_{2}$ \\
\hline Microbial process & Methanogenesis & $\begin{array}{l}\text { Sulphate } \\
\text { reduction }\end{array}$ & Denitrification & Nitrification \\
\hline Electron acceptor & $\mathrm{CO}_{2}$, hydrocarbons & $\mathrm{SO}_{4}$ & $\mathrm{NO}_{3}$ & $\mathrm{O}_{2}$ \\
\hline Redox, Eh (mV) & -300 to -400 & +100 too 300 & +100 to +320 & +320 to +600 \\
\hline
\end{tabular}

Table 1. Gradients and zones in soil/wetland beds (3).

As part of the Salix Project, we have attempted to demonstrate spatial and temporal heterogeneity both in laboratory microcosms and in a willow vegetation filter bed in the field by measuring in situ concentrations of dissolved gases using the technique of Membrane Inlet Mass Spectrometry (MIMS). Such measurements may provide direct evidence of microbial activity at specific locations in the bed and of the influence of plant roots on the sub-surface environment. The role of wetland plants such as reed (Phragmites australis) in supplying oxygen via the roots to the soil matrix is the subject of considerable debate, and relevant measurements of gases in the rhizoshere and soil matrix are very difficult to make $(4,5)$.

\section{MEASUREMENT OF DISSOLVED GAS CONCENTRATIONS}

MIMS can provide continuous and simultaneous monitoring of the concentrations of several dissolved gases or volatile species. The inlet probe can be placed up to a meter into a sample with minimal disturbance and measures with a spatial resolution of $1 \mathrm{~mm}(6)$. It has been used to study microbial activities in a variety of environments such as peat bogs, estuarine sediments and cheese.

Dissolved gas concentrations were measured using a quadropole mass spectrometer (Hiden Analytical Ltd, Warrington, UK) fitted with a 4 way manifold and stainless steel capillary probes (1.56 mm O.D., $0.5 \mathrm{~mm} \mathrm{I.D.)} \mathrm{with} \mathrm{silicon} \mathrm{rubber} \mathrm{membrane} \mathrm{inlets} \mathrm{(Figure} \mathrm{1).} \mathrm{The}$ partial pressures measured at mass to charge ratios $(\mathrm{m} / \mathrm{z})$ of $32,44,15,28,2,40$, and 64 were used to monitor concentrations of $\mathrm{O}_{2}, \mathrm{CO}_{2}, \mathrm{CH}_{4}, \mathrm{~N}_{2}, \mathrm{H}_{2}, \mathrm{H}_{2} \mathrm{~S}$, and $\mathrm{SO}_{2}$ respectively. This system allows continuous sequential sampling at 4 locations with a spatial resolution of 1 
$\mathrm{mm}$. An alternative needle probe of $0.5 \mathrm{~mm}$ diameter can provide greater spatial resolution but is less robust and hence not as suitable for field use (Figure 1).

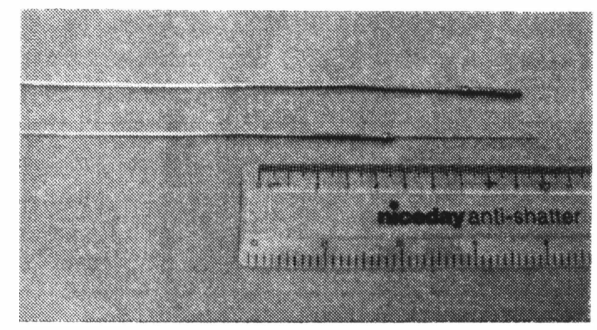

Figure 1. Probes for use with MIMS for monitoring dissolved gas concentrations.

In the field, the mass spectrometer was located on a platform at the side of the willow bed and the inlet of each probe was carefully inserted to the desired depth and allowed to equilibrate until a steady reading was achieved. Calibration was performed by placing the probes in tubes of leachate at the ambient temperature, which had been saturated with gas mixtures of known concentration. Liquid phase concentrations were calculated from the partial pressures using mole fractions. Values were divided by the comparative fraction of argon in the sample to compensate for differences between gaseous and liquid phase measurements.

\section{LABORATORY MICROCOSMS}

\section{Orygen release from willow roots}

A 3 month old rooted willow cutting was placed in a 1 litre stirred fermentor vessel filled with water. The water was sparged (gassed-out) with nitrogen to remove dissolved oxygen, the head-space sealed, and the vessel placed near a window. Gas concentrations were monitored with MIMS over a period of 17 hours under natural lighting. Oxygen was released from the roots during daylight, accumulating in the water, but at a slower rate during the subsequent dark period.

\section{Diurnal cycles of gas release from willow roots}

Dissolved gases in the fermentor vessel with its rooted willow cutting were continuously monitored over a period of 5 days. Clear diurnal cycles of $\mathrm{O}_{2}$ were seen with peaks coinciding with times of maximum insolation. Daily fluctuations of $\mathrm{CO}_{2}$ showed the reverse pattern, reducing in the light and accumulating in the dark. Over successive days, average $\mathrm{O}_{2}$ levels rose towards saturation whereas those of $\mathrm{CO}_{2}$ progressively declined.

\section{Orygenation by willow roots with added waste water}

In an experiment similar to the above, $1 \mathrm{ml}$ of artificial waste water (AWW, containing acetate, glucose, peptone, etc at 1/10 strength of cattle slurry), was added to the vessel initially, instead of sparging with nitrogen. The existing $\mathrm{O}_{2}$ was rapidly consumed and remained near zero for 2 days before starting to rise again, after the BOD load was consumed. $\mathrm{CO}_{2}$ showed the opposite pattern. The persistence of anaerobic conditions in the fermentor increased the higher the concentration of waste added, for example, with $2 \mathrm{ml}$ of AWW, 4 days elapsed before $\mathrm{O}_{2}$ was seen to accumulate. 


\section{FIELD STUDIES}

\section{Willow bed vegetation filter}

The vegetation filter examined in this study is part of a constructed wetland system designed to treat landfill leachate from the Nantmel landfill site in Powys, Wales and has been previously described by Kowalik et.al. (7). Two soil filled beds (each $4 \mathrm{~m}$ by $10 \mathrm{~m}$, with puddled clay liners), were planted in 1990 with a mixture of willow varieties (Salix viminalis, S. dasyclados, S. cinerea and the cultivar Salix Delamere). Landfill leachate collects in a large holding lagoon from which it is pumped intermittently, directly onto the surface at one end of the willow bed. Leachate percolates through the soil in the bed and drains into a sump at the far end where its level is controlled by a pump (Figure 2). Hence the frequency of inflow and outflow depends on the amount of rainfall, and the flow regime is tidal in character.

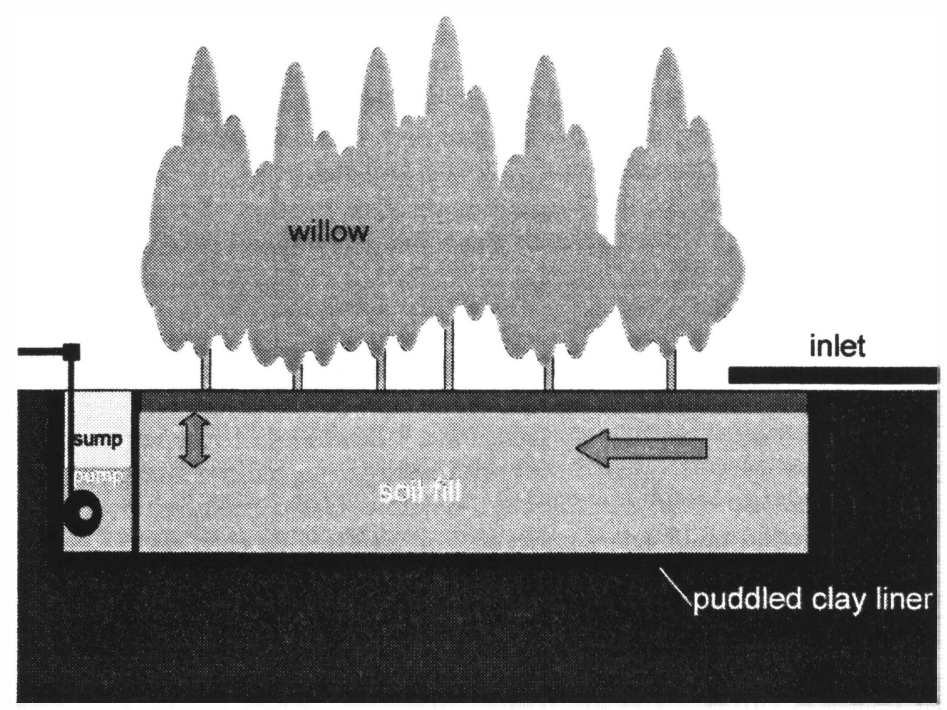

Figure 2. The willow vegetation filter bed at Nantmel landfill site, Wales.

\section{Depth profiles in the willow bed}

Simultaneous depth profiles of dissolved gas concentrations were made at 4 locations in the flooded bed by pushing each probe down to $30 \mathrm{~cm}$ depth through successive $5 \mathrm{~cm}$ intervals, allowing time for the probe to equilibrate at each level. Although $\mathrm{O}_{2}$ showed in general a decline with depth, particularly below $15 \mathrm{~cm}$, there was $\mathrm{O}_{2}$ present throughout the profile. $\mathrm{CO}_{2}$ and $\mathrm{CH}_{4}$ were present in higher amounts in the lower part of the profile but $\mathrm{CH}_{4}$ was also evident close to the surface. The 4 profiles differed considerably in detail, indicating a large degree of local heterogeneity in gas distribution and hence a variety of micro-environments, as anticipated. 
Similar depth profiles were made to compare the bed flooded with leachate water and in its dried-out condition, 1 week after the inlet pump was stopped. Below $42 \mathrm{~cm}$ the bed was permanently flooded and $\mathrm{O}_{2}$ rapidly declined to zero in the waterlogged zone in both cases. In flowing conditions both $\mathrm{CO}_{2}$ and $\mathrm{CH}_{4}$ showed a steady rise in concentration below $25 \mathrm{~cm}$, whereas in the dried out bed production of $\mathrm{CH}_{4}$ and, to a lesser degree, $\mathrm{CO}_{2}$ is much lower, presumably due to a reduced input of organic matter limiting heterotrophic activity.

A depth profile at a finer resolution was made with a single probe inserted by $2.5 \mathrm{~mm}$ depth increments, starting $20 \mathrm{~cm}$ below the surface. This profile showed clear evidence of oxygenated pockets at depth, in the saturated zone of the bed, and an inverse relationship between concentrations of $\mathrm{O}_{2}$ and $\mathrm{CO}_{2}$.

\section{Mini-rhizotron camera system}

In order to view undisturbed depth profiles of fine roots in the willow bed, clear perspex tubes, or mini-rhizotrons, $5 \mathrm{~cm}$ in diameter, were inserted in the willow bed in spring 2001 and subsequently examined after the summer period of root growth. To enable photographic profiles to be made, we have developed a low-cost, compact, digital camera system with LED illumination powered from the USB port of a laptop computer. This can be used in combination with the MIMS probe to determine in situ gas concentrations at precise locations either in proximity to, or away from a plant root.

Direct observation of the depth distribution of roots in a vegetation filter bed would be valuable in relation to oxygenation potential. In Phragmites australis, fine laterals at the base of roots were found to release more oxygen than old roots (5). The distribution of fine roots in stands of willow is generally most abundant in the upper $10 \mathrm{~cm}$ but is subject to rapid turnover throughout the year (8).

\section{The influence of a plant root on an oxygen depth profile in the willow bed}

A detailed profile in $2.5 \mathrm{~mm}$ steps, starting from $20 \mathrm{~cm}$ depth, was made with the MIMS probe adjacent to the mini-rhizotron tube, noting the positions of main and lateral roots in relation to the probe inlet. Peaks of $\mathrm{O}_{2}$ occurred adjacent to lateral roots and $\mathrm{O}_{2}$ levels were generally higher in proximity to visible roots. This appears to provide direct evidence of local enrichment of the matrix with $\mathrm{O}_{2}$ by willow roots.

\section{Influence of weather on diurnal cycles of in-situ gas concentrations}

Diurnal cycles of $\mathrm{O}_{2}, \mathrm{CO}_{2}$ and $\mathrm{CH}_{4}$ were monitored in the willow bed with a single MIMS probe over a period of 12 days in May 2001. Concentrations of $\mathrm{O}_{2}$ fluctuated between zero and $300 \mu \mathrm{M}$ (anaerobic to fully saturated) between day and night, during a period of 3 days of bright sunshine and high temperatures. On cloudy days, fluctuations were less pronounced. These results suggest that the bed is capable of becoming fully oxygenated in a short time in bright, sunny conditions, and indicate a remarkable capacity for oxygen transfer on the part of the willow roots.

\section{The effect of non-flowing conditions on diurnal cycles of gases in the willow bed}

Diurnal cycles of $\mathrm{O}_{2}, \mathrm{CO}_{2}$ and $\mathrm{CH}_{4}$ were monitored as before at a depth of $20 \mathrm{~cm}$ at 4 locations with 4 MIMS probes. After a period of normal, intermittent flow of leachate water, the inlet and outlet pumps were stopped and the bed allowed to remain fully saturated. At 3 of 
the probes $\mathrm{O}_{2}$ declined rapidly to zero, whereas $\mathrm{CO}_{2}$ and $\mathrm{CH}_{4}$ continued to show diumal cycles. At the $4^{\text {th }}$ probe, $\mathrm{O}_{2}$ concentration continued to cycle, probably because the probe was close to a willow root, which provided a local enrichment effect sufficient to exceed local $\mathrm{O}_{2}$ consumption.

This speculation is supported by the results of a tracer experiment which show that the willow bed acts as a well-mixed flowing system, rather than a "plug-flow" system. 1 litre of fluorescein dye was poured onto the upstream surface of the bed, and the outlet sampled every half-hour over the following 4 days. As this took place during a rainy period, the inlet pump was activated about every $3 \mathrm{~min}$, delivering $70 \mathrm{l}$ at each pulse. Dye appeared in the first sample taken (after $1 / 2 \mathrm{~h}$ ), rising to a peak after 1 hour, before declining steadily over the following day, indicating the bed to be well mixed. This suggests that, under flowing conditions, the influence of plant-derived oxygenation on the aerobic breakdown of waste is distributed through the volume of the bed. It may explain how the plant roots can apparently create and maintain aerobic conditions whereas, if the flow of waste water is stopped, the bulk of the bed matrix rapidly becomes anaerobic.

\section{SUMMARY}

- Diurnal cycles in the concentrations of $\mathrm{O}_{2}, \mathrm{CO}_{2}$ and $\mathrm{CH}_{4}$ were shown to occur with a rooted willow cutting in a stirred microcosm.

- Dissolved gas profiles of the willow beds show considerable sub-surface spatial diversity. Generally, oxygen decreases with depth whereas methane and carbon dioxide increase with depth. Small pockets of gases were seen. Oxygen occurred throughout the profile.

- Microbial processes follow diurnal cycles. Oxygen is released from willow roots during daylight. Methane and carbon dioxide accumulate during the dark.

- The high degree of mixing distributes oxygenated water throughout the bed. Stopping flow allowed conditions to become anaerobic.

The MIMS technique, particularly in conjunction with the mini-rhizotron camera appears to offer considerable potential for direct measurement of sub-surface environments in constructed wetlands, particularly in respect of the microbial processes occurring in the bed, and the oxygenation capacity of willow vegetation filters.

\section{ACKNOWLEDGEMENTS}

This work has been funded by EU (EAGGF) and UK (RDG) funds as part of the Salix Project. We acknowledge the work of Mr Jolyon Wicks (Skye Instruments Ltd) in designing and developing the mini-rhizotron camera system. We are grateful to Dr Steve Simmons (Powys County Council) for providing field site facilites. 


\section{REFERENCES}

1. Brix H. (1987) Treatment of wastewater in the rhizosphere of wetland plants - the root zone method. Wat. Sci. Tech. 19, 107-119.

2. D'Angelo, E.M..; Reddy, K.R. Unpublished results.

3. Kowalik, P.J. Pers. Comm.

4. Brix H. (1997) Do macrophytes play a role in constructed treatment wetlands? Wat. Sci. Tech.e35, 11-17.

5. Armstrong, J. and Armstrong W. (1988) Phragmites australis - a preliminary study of soil oxidising sites and internal gas transport parthways. New Phytol. 108, 373-382.

6. Lloyd D., Thomas K., Price D., O’Neil B., Oliver K. and Williams T. (1996) A membrane-inlet mass spectrometer miniprobe for direct simultaneous measurement of multiple gas species with spatial resolution of $1 \mathrm{~mm}$. Journal of Microbiological Methods, $25,145-151$.

7. Kowalik P.J, Slater, F.M. \& Randerson F.M. (1996) Constructed wetlands for landfill leachate treatment. In: Ecotechnics for a Sustainable Society: Proceedings from Ecotechnics 95 - International Symposium on Ecological Engineering. Eds L. Thofelt \& A. Englund, Mid Sweden University, Hamosand, Sundsvall, Ornskoldsvik, Ostersund.

8. Rytter R-M and Hansson A-C. (1996) Seasonal amount, growth and depth distribution of fine roots in an irrigated and fertilized Salix Viminalis L. plantation. Biomass and Bioenergy $11,129-137$. 